\title{
Reflections on the role of publications by scientific societies in celebration of the 25th year for Acta Botanica Brasilica
}

\author{
From your sister society to the north: the Botanical Society of America
}

Upon the occasion of the $25^{\text {th }}$ year of publication of Acta Botanica Brasilica $(A B B)$ by the Brazilian Botanical Society, we offer some reflections on the importance of the American Journal of Botany to the Botanical Society of America. As the primary scientific journal of our society, publication began in 1914, 21 years after the society was founded in 1893. Our journal, as does $A B B$, accepts papers on every aspect of plant science. The journal is particularly rich in papers that focus on organismal approaches. Papers on plant genomics, molecular evolution, and community and ecosystem ecology are less well-represented, although research published in the journal informs these topics. Because of its organismal focus, the journal is an important resource for those researchers looking for information on plants. Our journals also attract interest in our societies, as researchers become aware of others sharing common research interests. Attendance at national meetings and interactions with other researchers is one outcome of publication of our journals. For many of us who were trained as botanists, our first introduction to the society was through meetings as students. For us, the journal has played a role as the venue to publish our research and for information on the important research of others in botany. Journals are the basic resource for fundamental research in science; most major scientific societies support some publication that contributes to the scientific compendium of knowledge in the world. However, as we approach our hundredth year of publication and as you celebrate your $25^{\text {th }}$ year, the publication world is changing rapidly due to electronic access. This rapidly changing landscape raises important questions for authors, societies, publishers, and researchers. Will the journal remain the important work, or will the actual article become the more important item for consideration? How will societies survive on a new business model, independent of the income from the purchase of the journal? If access to journals is free, who pays for costs of the peer review and editing to ensure that papers are of the highest quality? Time alone will answer these questions, but societies must be ready and carefully consider now how to meet the challenges ahead. Researchers need to think about paying to publish, rather than paying for the published material.
As we think about our journal and its importance for our society, the definitions of journal provide thought- provoking material. Of course, a definition of "journal", as the definition of" acta", is a periodical presenting articles on a particular subject such as plant science. The word "journal” however, has additional meanings, such as a personal record of occurrences, experiences, and reflections kept on a regular basis; a diary. And isn't that exactly what our journal does for our society? It presents the experiences and knowledge of our various researchers who have published their hypotheses, data, and conclusions over time in the journal. Looking back through the topics of the journal, we can trace the important emphases of the field of botany - from discovery of species and their geographical occurrences, the accumulation of these species into floras, and the growth patterns and processes of these organisms, to more detailed morphological and anatomical studies, through genetic and physiological processes influencing the form and structure of plants, to broad ecosystem relationships among all organisms including the plants and the physical factors that influence these organisms. At all levels of botanical investigation, we see shifts in experimental approaches with increasing use of molecular tools for studies on phylogenies, gene action, and cellular processes. Thus, the journal becomes a personal reflection of the growth and development of the society over the last century, and provides valuable information about the scientific process in plant biology. This observation leads directly to another definition of the word "journal" as an official record of daily proceedings, as of a legislative body or a ship's log. Perhaps not daily, but the monthly publication of the journal has provided an official record of the proceedings happening throughout the diverse research disciplines of the society. The journal provides an important historical thread that ties the society members together with all who have preceded us, and which we hope will continue to form that bond with future botanists.

In addition, the journal provides a record of the best in scientific research produced by a researcher. An article written according to strict guidelines and peer reviewed to provide validity for the results becomes part of the scientific record. Journal articles document the complete research 
process and provide a means of repeating the research to verify the results. Students reading and discussing these articles in journals learn the scientific method and the rules for scientific publication, as students have for centuries. They will continue to do so, whether these articles are produced in printed format on paper or in electronic online publications, which is certainly the way most scientists now are accessing scientific literature. Given the ubiquity of information on the web, endorsement of articles by a scientific society becomes even more critical to verify the authenticity and value of the work. A web-based, "rate this article" approach may work in some cases, but not in scientific disciplines.

Journals have another role as well- they can lead the way by encouraging research directions that are likely to lead to new and promising results. For example, the editors of journals and the members of a society can solicit contributions for special issues of a journal that bring together papers on topics that are important to a field, but may not have been well-represented in the journal. These special issues may have synergistic effects by heightening an awareness of research approaches especially beneficial to a discipline. Special issues may also be useful for reflecting on the status of a field, and integrating research approaches over a broad range of disciplines. Two recent issues of the American Journal of Botany exemplify these approaches. The journal celebrated the Darwin Bicentennial by publishing a special issue in 2009 on Darwin's "abominable mystery," the apparently sudden appearance of flowering plants in the Cretaceous Period. This issue of the journal contained a very broad array of papers, emphasizing topics ranging from paleobotany to molecular genetics. A reader of this issue would gain a very comprehensive approach to research questions surrounding the evolution of flowering plants, and perspective on how scientists in other disciplines apply their approach to the problem. A more recent issue of the journal published in 2011 was devoted to biodiversity- in the broadest sense possible. Topics covered included diversification of ecosystems throughout paleohistory, evolutionary diversification of flowering plants, diversity in microbial communities, and the effects of species invasion on biodiversity. Ecosystem and global change issues were especially well represented, and might generate more attention to these topics in future issues of the American Journal of Botany. These special issues, which have been highly cited, indicate the role of a journal in contributing to the growth of a particular discipline or area of research, and indicate that even in an age when most readers download articles rather than issues, the synthesis of ideas in a single location, electronic or otherwise, can be influential.

We live in an age where communication often seems in stantaneous, and the flow of ideas so rapid that new research directions rapidly gain momentum. The same forces that promote this exchange of information may have negative consequences for our societies, unless we think carefully about new business models for our journals. Several models exist, such as the traditional approach where the reader/ user pays, models where the author pays for publishing, institutional sponsorship methods, marketing support (but these do not work well for specialized scientific articles), providing portions of articles or special articles for free but requiring payment for complete articles or issues of journals, or hybrid models of these methods. The American Journal of Botany offers free access after one year to all the articles but if researchers or libraries wish to have more instantaneous access, they pay. All these models have issues that have been discussed in great detail. As scientific societies we need to be part of the discussion on the business models of openaccess publishing because we must generate the resources to continue to produce solid, verifiable scientific articles that are openly accessible to all. We owe it to those who established the high standards for our society publications and we owe it to the students and researchers of the future to provide a continuous, historical, reliable, and trusted resource and outlet for the best of botanical information.

Judith E. Skog BSA President

Stephen G. Weller BSA President-elect 